\title{
Safety and efficacy of coronary
} angiography and percutaneous coronary intervention via distal transradial artery access in the anatomical snuffbox: a single-centre prospective cohort study using a propensity score method

Feng $\mathrm{Li}^{1 \dagger}{ }^{1}$, Gan-Wei Shi ${ }^{1}$, Xiao-Long Yu ${ }^{2 \dagger}$, Rui-Xiao Song ${ }^{2}$, Jian-Qiang Xiao ${ }^{1}$, Hao-Min Huang ${ }^{1}$, La-Mei Li ${ }^{1}$, Liu-Yan Zhang ${ }^{1}$, Chun Gong ${ }^{1}$ and Gao-Jun Cai ${ }^{*}$

\begin{abstract}
Background: This study investigated the safety and efficacy of coronary angiography (CAG) and percutaneous coronary intervention $(\mathrm{PCl})$ via distal transradial artery access (d-TRA).

Methods: For this single-centre prospective cohort study, a total of 1066 patients who underwent CAG or PCI procedures from September 2019 to November 2020 were included. Patients were divided into two groups: the d-TRA group (346) and the conventional transradial artery access (c-TRA) group (720) based on access site. A total of 342 pairs of patients were successfully matched using propensity score matching (PSM) for subsequent analysis.

Results: No significant differences in puncture success rate, procedural method, procedural time, sheath size, contrast dosage or fluoroscopy time were noted between the two groups. The puncture time in the d-TRA group was longer than that in the c-TRA group $(P<0.01)$, and the procedure success rate was lower than that in the c-TRA group ( $90.94 \%$ vs. $96.49 \%, P=0.01)$. The haemostasis time in the d-TRA group was shorter than that in the c-TRA group $(P<0.01)$, and the visual analogue scale (VAS) was lower than that in the c-TRA group $(P<0.01)$. In addition, the prevalence of bleeding and haematoma in the d-TRA group was lower than that in the c-TRA group $(1.75 \%$ vs. $7.31 \%$, $P<0.01 ; 0.58 \%$ vs. $3.22 \%, P=0.01$, respectively). No significant difference in the incidence of numbness was noted between the two groups. No other complications were found in two groups.
\end{abstract}

Conclusion: d-TRA is as safe and effective as c-TRA for CAG and PCI. It has the advantages of improved comfort and fewer complications.

\footnotetext{
*Correspondence: cgj982@126.com

${ }^{\dagger}$ Feng Li and Xiao-Long Yu have contributed equally to this work

${ }^{1}$ Department of Cardiology, Wujin Hospital Affiliated with Jiangsu

University, The Wujin Clinical College of Xuzhou Medical University, 2

North Yongning Road, Changzhou 213017, Jiangsu Province, People's

Republic of China

Full list of author information is available at the end of the article
}

(C) The Author(s) 2022. Open Access This article is licensed under a Creative Commons Attribution 4.0 International License, which permits use, sharing, adaptation, distribution and reproduction in any medium or format, as long as you give appropriate credit to the original author(s) and the source, provide a link to the Creative Commons licence, and indicate if changes were made. The images or other third party material in this article are included in the article's Creative Commons licence, unless indicated otherwise in a credit line to the material. If material is not included in the article's Creative Commons licence and your intended use is not permitted by statutory regulation or exceeds the permitted use, you will need to obtain permission directly from the copyright holder. To view a copy of this licence, visit http://creativecommons.org/licenses/by/4.0/. The Creative Commons Public Domain Dedication waiver (http://creativeco mmons.org/publicdomain/zero/1.0/) applies to the data made available in this article, unless otherwise stated in a credit line to the data. 
Trail registration Chinese Clinical Trial Registry, ChiCTR1900026519.

Keywords: Coronary atherosclerotic disease, Percutaneous coronary intervention, Distal transradial artery access, Anatomical snuffbox

\section{Background}

Coronary atherosclerotic disease (CAD) is the most common cause of human death worldwide [1]. Femoral artery access is a classical access route for coronary angiography (CAG) and percutaneous coronary intervention (PCI). However, this rote has some complications, such as bleeding, haematoma and pseudoaneurysm, and the risk of lower limb thrombosis and pulmonary embolism is increasing due to a long bedridden time after the procedure [2]. During the past three decades, conventional transradial artery access (c-TRA) has shown the advantage of few complications and has gradually replaced femoral artery access as the routine for CAG and PCI [3, 4]. However, c-TRA also has some complications, such as radial artery occlusion, vascular injury, spasm, pseudoaneurysm, arteriovenous fistula, access site bleeding and nerve injury [5-8]. In addition, if the puncture of the c-TRA is failure will be crossover to the femoral artery in a non-negligible proportion of cases. However, it is associated with worse prognosis which can be predicted $[9,10]$. In 2014, Kaledin et al. [11] described distal transradial artery access (d-TRA) as the default technique for coronary procedures, and Roghani-Dehkordi et al. [12] highlighted the advantages of d-TRA among hand arterial access routes at a Middle Eastern transradial course in 2016. On the basis of those experiences, Kiemeneij [13] promoted left d-TRA in the anatomic snuffbox (AS) for improved procedure ergonomics and patient comfort in right-handed subjects. In recent years, an increasing number of studies have focused on the feasibility and safety of CAG and PCI via d-TRA [14]. However, only a few cohorts or randomized controlled trials have been performed to compare the safety and efficacy of CAG and PCI via d-TRA [15-17].

Here in, a prospective cohort study was performed to investigate the safety and efficacy of CAG and PCI via d-TRA using propensity score matching (PSM) in a Chinese population.

\section{Methods}

\section{Patient population and study design}

A total of 1066 patients who underwent CAG or PCI procedures from September 2019 to November 2020 in Wujin Hospital affiliated with Jiangsu University were included. The exclusion criteria were as follows: (1) patients with acute myocardial infarction undergoing emergency PCI; (2) radial artery pulse that cannot be palpated in the distal or conventional transradial artery; (3) infection in the access site; (4) patients with severe liver/kidney failure or coagulation dysfunction; and (5) patients with symptomatic peripheral vascular disease or Raynaud's syndrome. According to the initial puncture site, the patients were divided into two groups: the d-TRA group $(\mathrm{n}=346)$ and the c-TRA group $(\mathrm{n}=720)$. To eliminate confounding factors, PSM at a 1:1 ratio was used between the two groups. Finally, 342 pairs of patients were successfully matched for subsequent analysis. The study was vetted and approved by the Ethics Committee of Wujin Hospital affiliated with Jiangsu University, and all the patients signed the informed consent form.

\section{Procedures}

The right hand was the primary access side for the procedures. c-TRA or d-TRA was selected according to operator preference. For the d-TRA group, the access site was in the AS. Accordingly, in the c-TRA group, the access was in the proximal $3 \mathrm{~cm}$ of the wrist's transverse striation. In the d-TRA group, the patient was asked to place the forearm in a natural vertical position and to grasp his thumb under the other four fingers to expose the AS area. For the c-TRA group, the arm abduction was $70^{\circ}$, and the wrist was overextended, which fully exposed the radial artery. Following disinfection, 2\% lidocaine was used for local anaesthesia. Then Seldinger's technique puncture was performed in the AS and the wrist. The puncture was performed with a $20-\mathrm{G}$ puncture needle and a $0.025^{\prime \prime}$ guidewire (Terumo Corporation, Tokyo, Japan, match a 6 French introducer sheath). After a successful puncture, an introducer sheath was placed, and $3000 \mathrm{U}$ heparin and $200 \mu \mathrm{g}$ nitroglycerine were administered through the side-port of the sheath. Then, a 5 French TIG catheter was used to complete the CAG. In cases of PCI, the procedure was continued after changing the guide catheter. After the procedure, a gauze was used in both the d-TRA and c-TRA groups for haemostasis (Fig. 1). The procedure crossed over to the left d-TRA if the puncture failed in the d-TRA group, and the left c-TRA was used in the c-TRA group. 

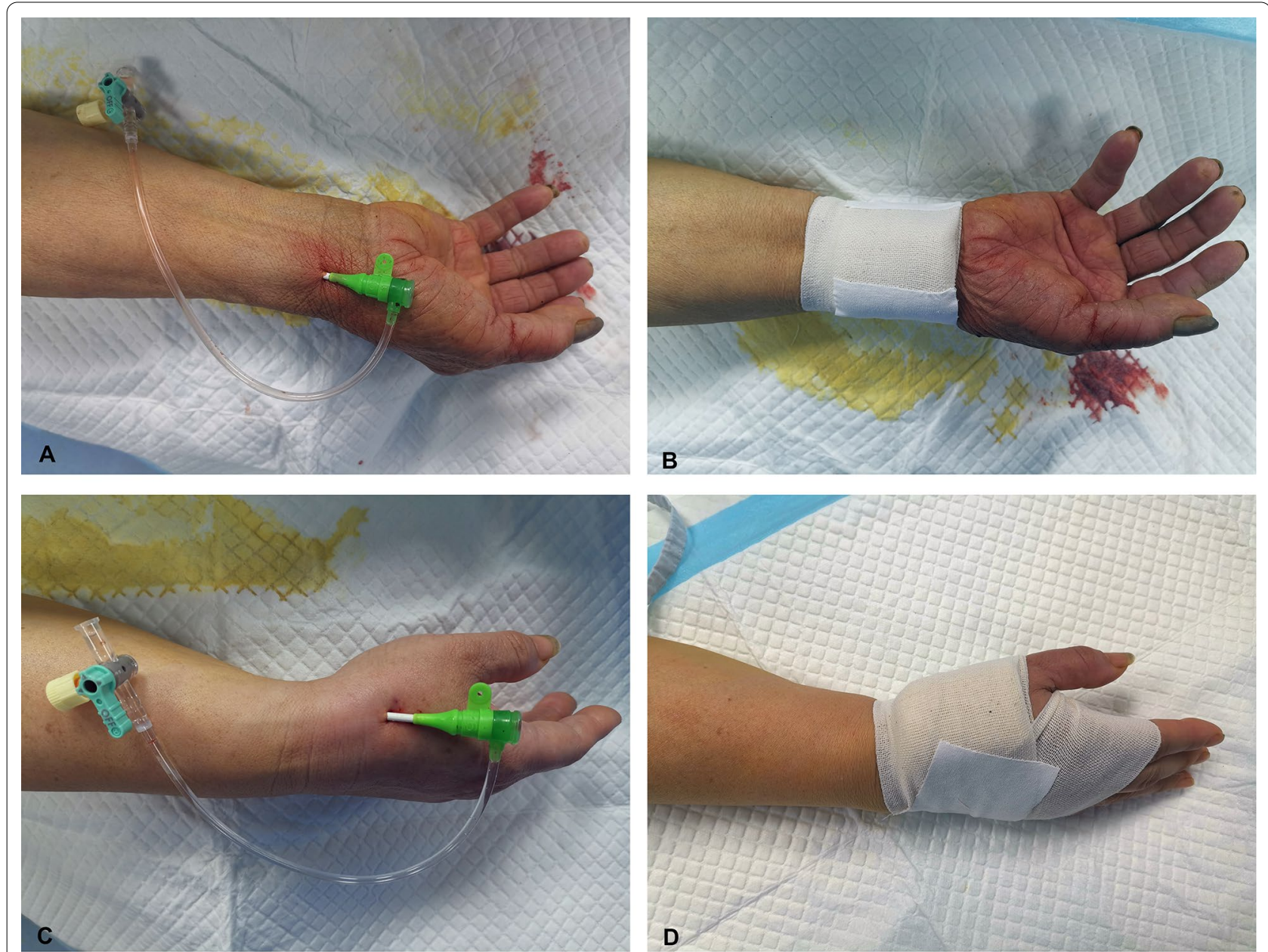

Fig. 1 Catheterization by d-TRA and c-TRA. A Implantation of the sheath via c-TRA. B Haemostasis of the c-TRA. C Implantation of the sheath via d-TRA. $\mathbf{D}$ Haemostasis of the d-TRA

\section{Clinical observation index and performance assessment}

Patient demographic and clinical characteristics, laboratory examination, and intraprocedural and post procedure data of the two groups were recorded in an electronic database. The data included the following: sex, age, body mass index (BMI), previous medical history, uric acid (UA), creatinine (Cr), glucose (Glu), total cholesterol (TC), triglyceride (TG), low-density lipoprotein cholesterol (LDL-C), high-density lipoprotein cholesterol (HDL-C), glycosylated haemoglobin (HbA1c), puncture time, puncture success rate, procedural time, procedure success rate, contrast dosage, fluoroscopy time, visual analogue scale (VAS), access site with or without haemorrhage and haematoma. If pulsatile swelling or a palpable thrill was noted at the access site after the procedure, an ultrasound examination was used to confirm the diagnosis of arteriovenous fistula or pseudoaneurysm. The outcomes and performance of the procedures were measured as follows: (1) puncture time, time from the beginning of the puncture to the insertion of the artery sheath; (2) puncture success rate determined by arterial blood ejection from the puncture sheath after a successful puncture; (3) procedure success, which is noted when the whole procedure was completed from the same access; (4) haemostasis time, time from the beginning of compression on the access site to the complete decompression; (5) VAS [18] with a $10-\mathrm{cm}$ straight line divided into 10 equal parts to rate pain with 0 indicating no pain and 10 for extreme pain (the patient would note the corresponding position according to the puncture site's compression and the haemostasis, which determine the patient's pain level); (6) bleeding was classified by the BARC (Bleeding Academic Research Consortium) criteria [19]; and (7) haematoma was assessed according to the EASY (Early Discharge After Transradial Stenting of Coronary Arteries) classification [20]. 


\section{Propensity score matching}

In this study, to minimize selection bias of the two groups, a 1:1 propensity score matching (PSM) analysis was performed to adjust the baseline difference. Factors, such as age, sex, BMI, previous medical history, UA, CR, Glu, TC, TG, LDL-C, HDL-C, and HbA1c were included in the PSM model using greedy nearest neighbor matching without replacement and with a caliper of 0.01 . Standardized differences were evaluated before and after matching to assess the performance of the model. Standardized differences of less than $10.0 \%$ indicated a relatively small imbalance.

\section{Statistical analysis}

All the analyses were performed with the statistical software packages R (http://www.R-project.org, The R Foundation) and EmpowerStats (http://www.empowerstats. com, X\&Y Solutions, Inc, Boston, MA). Continuous variables with a nonnormal distribution and categorical variables were expressed as medians/quartiles [M/(P25, P75)] and counts or percentages [n (\%)], respectively, and the differences were detected with a nonparametric test and chi-square test, respectively. A $P$ value $<0.05$ was considered statistically significant.

\section{Results}

Comparison of baseline data before and after matching between the two groups

The patient demographic and clinical characteristics are shown in Table 1. Significant differences in the percentage of smoking and TG levels were noted between the two groups before matching. Using PSM, 342 pairs of patients in the d-TRA and TRA groups were successfully matched, and no statistically significant differences in fifteen confounding variables were noted between the two groups (Table 1 and Fig. 2).

\section{Comparison of the effectiveness between the matched groups}

No significant differences in sheath size, procedure method, contrast dosage or fluoroscopy time were noted between the two groups $(P>0.05)$. The puncture time in the d-TRA group was longer than that in the c-TRA group $[80(70,100)$ s vs. $60(60,66)$ s, $P<0.01]$, and the procedure success rate was lower than that in

Table 1 Comparison of baseline data before and after matching between two groups

\begin{tabular}{|c|c|c|c|c|c|c|c|c|}
\hline \multirow[t]{2}{*}{ Characteristic } & \multicolumn{2}{|l|}{ Before matching } & \multirow[t]{2}{*}{$x^{2}(Z)$} & \multirow[t]{2}{*}{$P$} & \multicolumn{2}{|l|}{ After matching } & \multirow[t]{2}{*}{$x^{2}(Z)$} & \multirow[t]{2}{*}{$P$} \\
\hline & d-TRA $(\mathrm{N}=346)$ & $c-T R A(N=720)$ & & & d-TRA (N=342) & $c-T R A(N=342)$ & & \\
\hline Male [n (\%)] & $214(61.85)$ & $458(63.61)$ & 0.31 & 0.58 & $211(61.70)$ & $208(60.80)$ & 0.06 & 0.81 \\
\hline Age $\left[M /\left(P_{25}, P_{75}\right), y r s\right]$ & $66.50(58.00,72.25)$ & $67.00(59.00,73.00)$ & -0.51 & 0.61 & $66.50(58.00,72.00)$ & $67.00(59.00,73.00)$ & -0.54 & 0.59 \\
\hline $\begin{array}{l}\mathrm{BMI}\left[\mathrm{M} /\left(P_{25}, P_{75}\right), \mathrm{kg} /\right. \\
\left.\mathrm{m}^{2}\right]\end{array}$ & $24.26(22.34,26.69)$ & $24.80(22.43,26.87)$ & -1.05 & 0.30 & $24.26(22.34,26.69)$ & $24.45(22.04,26.56)$ & -0.32 & 0.75 \\
\hline Smoking [n (\%)] & $142(41.04)$ & $216(30.00)$ & 12.77 & $<0.01$ & $139(40.60)$ & $124(36.30)$ & 1.39 & 0.24 \\
\hline $\mathrm{EH}[\mathrm{n}(\%)]$ & $248(71.68)$ & $514(71.39)$ & 0.01 & 0.92 & $245(71.60)$ & $243(71.10)$ & 0.03 & 0.87 \\
\hline DM [n (\%)] & $94(27.17)$ & $183(25.42)$ & 0.37 & 0.54 & $91(26.60)$ & $92(26.90)$ & 0.01 & 0.93 \\
\hline HLD [n (\%)] & $13(3.76)$ & $42(5.83)$ & 2.06 & 0.15 & $13(3.80)$ & $12(3.50)$ & 0.04 & 0.84 \\
\hline $\begin{array}{l}\text { UA }\left[M /\left(P_{25}, P_{75}\right)\right. \\
\text { umol/L] }\end{array}$ & $335.75(278.63,403.75)$ & $335.55(279.30,404.90)$ & -0.13 & 0.89 & $335.45(278.25,400.55)$ & $332.25(277.03,395.05)$ & -0.56 & 0.58 \\
\hline $\begin{array}{l}\mathrm{Cr}\left[\mathrm{M} /\left(P_{25}, P_{75}\right)\right. \\
\mu \mathrm{mmol} / \mathrm{L}]\end{array}$ & $72.65(60.00,83.93)$ & $70.80(60.20,81.08)$ & -1.28 & 0.20 & $72.55(59.98,83.83)$ & $71.25(60.60,82.70)$ & -0.14 & 0.89 \\
\hline $\begin{array}{l}\text { Glu }\left[M /\left(P_{25}, P_{75}\right)\right. \\
\mathrm{mmol} / \mathrm{L}]\end{array}$ & $5.18(4.67,6.05)$ & $5.22(4.67,6.38)$ & -1.09 & 0.28 & $5.18(4.67,6.06)$ & $5.18(4.64,6.35)$ & -0.45 & 0.65 \\
\hline $\begin{array}{l}\mathrm{TC}\left[M /\left(P_{25}, P_{75}\right)\right. \\
\mathrm{mmol} / \mathrm{L}]\end{array}$ & $3.95(3.20,4.72)$ & $3.99(3.24,4.80)$ & -0.64 & 0.52 & $3.95(3.20,4.72)$ & $3.80(3.15,4.66)$ & -1.34 & 0.18 \\
\hline $\begin{array}{l}\mathrm{TG}\left[\mathrm{M} /\left(\mathrm{P}_{25}, P_{75}\right)\right. \\
\mathrm{mmol} / \mathrm{L}]\end{array}$ & $1.46(1.04,2.03)$ & $1.58(1.12,2.32)$ & -2.91 & $<0.01$ & $1.48(1.06,2.03)$ & $1.46(1.08,2.07)$ & -0.56 & 0.58 \\
\hline $\begin{array}{l}\mathrm{LDL}-\mathrm{C}\left[\mathrm{M} /\left(P_{25}, P_{75}\right)\right. \\
\mathrm{mmol} / \mathrm{L}]\end{array}$ & $2.54(2.02,3.18)$ & $2.69(2.04,3.33)$ & -1.79 & 0.07 & $2.56(2.03,3.18)$ & $2.60(1.96,3.22)$ & -0.33 & 0.74 \\
\hline $\begin{array}{l}\mathrm{HDL}-\mathrm{C}\left[\mathrm{M} /\left(P_{25}, P_{75}\right)\right. \\
\mathrm{mmol} / \mathrm{L}]\end{array}$ & $1.09(0.92,1.31)$ & $1.06(0.93,1.25)$ & -0.66 & 0.51 & $1.09(0.92,1.31)$ & $1.08(0.93,1.26)$ & -0.35 & 0.73 \\
\hline $\mathrm{HbA} 1 \mathrm{c}\left[M /\left(P_{25}, P_{75}\right), \%\right]$ & $6.10(5.80,6.80)$ & $6.00(5.70,6.90)$ & -1.05 & 0.30 & $6.10(5.80,6.80)$ & $6.10(5.70,7.00)$ & -0.40 & 0.69 \\
\hline
\end{tabular}

d-TRA distal transradial artery access, c-TRA conventional transradial artery access, BMI body mass index, EH essential hypertension, DM diabetes mellitus, HLD hyperlipidemia, UA uric acid, Cr creatinine, Glu glucose, $T C$ total cholesterol, $T G$ triglyceride, $L D L-C$ low-density lipoprotein cholesterol, $H D L$ - $C$ high-density lipoprotein cholesterol, $\mathrm{HbA1c}$ glycated hemoglobin 


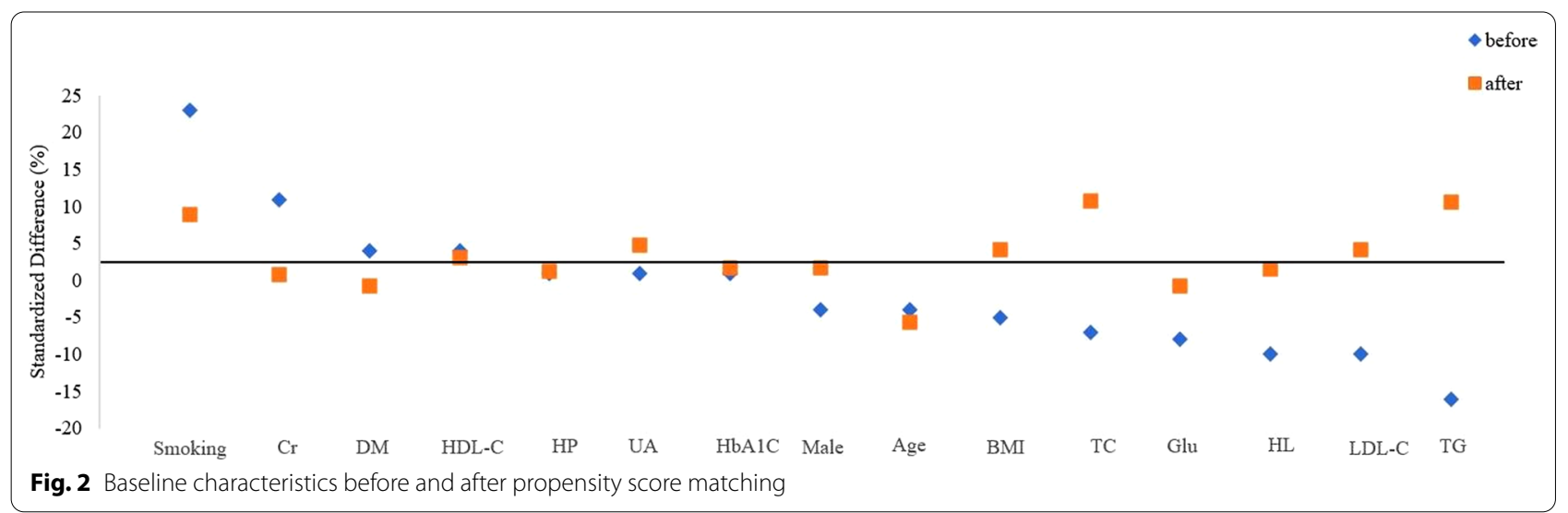

the c-TRA group $(90.94 \%$ vs. $96.49 \%, P=0.01)$. However, interestingly, the puncture success rate and the procedural time were not significantly different between the two groups $(93.57 \%$ vs. $96.49 \%, P=0.15 ; 35$ $(20,60)$ vs. $30(20,60), P=0.37$, respectively, Table 2$)$. Among the patients with successful puncture in the d-TRA group, a guide wire could not be inserted into the distal radial artery in seventeen patients. Of these, the sheath was finally inserted with the assistance of the working guide wire (0.014" Runthrough NS) in eight patients. Patients in the d-TRA group for whom the procedure was not successful all completed the procedure through crossover to the left d-TRA. For the patients in the c-TRA group for whom the procedure was not successful, all procedures were ultimately completed upon crossover to the left c-TRA. No patients required switching to the femoral artery access.

Subgroup analysis of the d-TRA group stratified by sex, age, BMI, essential hypertension (EH), diabetes mellitus (DM) and smoking showed that female patients, nonsmoking patients, patients with $\mathrm{EH}$ and without DM had a higher puncture success rate, which increased gradually with age and BMI. However, no statistically significant differences were noted among the different stratification factors (Additional file 1: Fig. S1).

Table 2 Comparison of the effectiveness between the matched groups

\begin{tabular}{|c|c|c|c|}
\hline Characteristic & d-TRA $(N=342)$ & $\mathrm{c}-\mathrm{TRA}(\mathrm{N}=342)$ & $P$ \\
\hline Puncture time $\left[M /\left(\mathrm{P}_{25}, \mathrm{P}_{75}\right), \mathrm{s}\right]$ & $80(70,100)$ & $60(60,66)$ & $<0.01$ \\
\hline Puncture success rate [n (\%)] & $320(93.57)$ & $330(96.49)$ & 0.15 \\
\hline Sheath $[n(\%)]$ & & & 0.32 \\
\hline $6 \mathrm{~F}$ & $341(99.71)$ & $339(99.12)$ & \\
\hline $7 F$ & $1(0.29)$ & $3(0.88)$ & \\
\hline Procedural method [n (\%)] & & & 0.18 \\
\hline CAG & $219(64.04)$ & $202(59.06)$ & \\
\hline $\mathrm{PCl}$ & $123(35.96)$ & $140(40.94)$ & \\
\hline $\operatorname{CAD}[\mathrm{n}(\%)]$ & $250(73.10)$ & $275(80.41)$ & 0.02 \\
\hline Number of diseased vessels [n (\%)] & & & 0.23 \\
\hline Single & $72(28.80)$ & $97(35.27)$ & \\
\hline Double & $90(36.00)$ & $84(30.55)$ & \\
\hline Multiple & $88(35.20)$ & $94(34.18)$ & \\
\hline Procedural time $\left[\mathrm{M} /\left(\mathrm{P}_{25}, \mathrm{P}_{75}\right), \mathrm{min}\right]$ & $35(20,60)$ & $30(20,60)$ & 0.37 \\
\hline Procedure success rate [n (\%)] & $311(90.94)$ & $330(96.49)$ & 0.01 \\
\hline Contrast dosage $\left[\mathrm{M} /\left(\mathrm{P}_{25}, \mathrm{P}_{75}\right), \mathrm{ml}\right]$ & $80(50,150)$ & $70(50,150)$ & 0.59 \\
\hline Fluoroscopy time $\left[M /\left(\mathrm{P}_{25}, \mathrm{P}_{75}\right), \mathrm{min}\right]$ & $7.54(3.17,15.11)$ & $6.21(2.47,14.14)$ & 0.07 \\
\hline
\end{tabular}

$C A G$ coronary angiography, $P C I$ percutaneous coronary intervention, $C A D$ coronary atherosclerotic disease 


\section{Comparison of the safety between the matched groups} The haemostasis time in the d-TRA group was shorter than that in the c-TRA group $[4(3,6) \mathrm{h}$ vs. $6(6,8) \mathrm{h}$, $P<0.01]$, and the VAS was lower than that in the c-TRA group $[3(2,3)$ vs. $4(3,5), P<0.01]$. All patients with bleeding in both groups were BARC type II, and haematoma was classified as EASY type I. The incidence of bleeding and haematoma in the d-TRA group was lower than that in the c-TRA group $(1.75 \%$ vs. $7.31 \%, P<0.01$; $0.58 \%$ vs. $3.22 \%, P=0.01$, respectively). Further analysis found that bleeding and haematoma were significantly different in CAG patients (bleeding: $0.91 \%$ vs. $5.94 \%$, $P<0.01$; haematoma: $0.00 \%$ vs. $2.48 \%, P=0.02$ ) but not in PCI patients (bleeding: $3.25 \%$ vs. $9.29 \%, P=0.05$; haematoma: $1.63 \%$ vs. $4.29 \%, P=0.21$ ). No significant difference in the incidence of numbness was noted between the two groups, and no other complications, such as pseudoaneurysm, arteriovenous fistula, and access site infection, were found (Table 3).

\section{Discussion}

The AS, a triangular-shaped space located on the lateral side of the wrist's dorsum, is clearly exposed when the thumb is stretched out. The AS is bound by the tendons of the extensor pollicis brevis and the abductor pollicis longus on the lateral side and the tendon of the extensor pollicis longus on the medial side. The base of the triangle is formed by the styloid process of the radius. The trapezium and scaphoid bones composed the bottom of the AS. In the AS region, the radial artery is easily palpated and becomes the best site for puncture given its superficial position and bony basement.

Table 3 Comparison of the safety between the matched groups

\begin{tabular}{|c|c|c|c|}
\hline Characteristic & d-TRA $(\mathrm{N}=342)$ & c-TRA $(\mathrm{N}=342)$ & $P$ \\
\hline $\begin{array}{l}\text { Haemostasis time }\left[M /\left(\mathrm{P}_{25}\right.\right. \\
\left.\left.\mathrm{P}_{75}\right), \mathrm{h}\right]\end{array}$ & $4(3,6)$ & $6(6,8)$ & $<0.01$ \\
\hline $\operatorname{VAS}\left[M /\left(\mathrm{P}_{25}, \mathrm{P}_{75}\right)\right]$ & $3(2,3)$ & $4(3,5)$ & $<0.01$ \\
\hline Bleeding (BARC II) [n (\%)] & $6(1.75)$ & $25(7.31)$ & $<0.01$ \\
\hline CAG & $2(0.91)$ & $12(5.94)$ & $<0.01$ \\
\hline $\mathrm{PCl}$ & $4(3.25)$ & $13(9.29)$ & 0.05 \\
\hline $\begin{array}{l}\text { Haematoma (EASY I) [n } \\
(\%)]\end{array}$ & $2(0.58)$ & $11(3.22)$ & 0.01 \\
\hline CAG & $0(0.00)$ & $5(2.48)$ & 0.02 \\
\hline $\mathrm{PCl}$ & $2(1.63)$ & $6(4.29)$ & 0.21 \\
\hline Numbness [n (\%)] & $3(0.88)$ & $4(1.17)$ & 0.70 \\
\hline Pseudoaneurysm [n (\%)] & $0(0 \%)$ & $0(0 \%)$ & 1.00 \\
\hline $\begin{array}{l}\text { Arteriovenous fistula [n } \\
(\%)]\end{array}$ & $0(0 \%)$ & $0(0 \%)$ & 1.00 \\
\hline Infection [n (\%)] & $0(0 \%)$ & $0(0 \%)$ & 1.00 \\
\hline
\end{tabular}

VAS visual analogue scale, BARC Bleeding Academic Research Consortium, EASY Early Discharge After Transradial Stenting of Coronary Arteries
The distal radial artery was first used by anaesthesiologists for intraoperative blood pressure monitoring [21]. Since Kiemenij [13] promoted the left d-TRA in 2017, an increasing number of cardiologic interventionalists have begun to pay attention to this access site $[14,22]$. Currently, the puncture and procedure success rates of d-TRA range from 70 to $100 \%$, and most of them are lower than those of c-TRA [14]. The preliminary experience of 34 patients in our centre showed that the puncture and procedure success rates were $91.18 \%$ and $85.29 \%$, respectively. Kiemeneij [13] reported that the procedure success rate was $88.57 \%$. Early clinical experience by Valsecchi et al. [23] showed that the overall feasibility was $90.39 \%$. A prospective observational study conducted in a Korean population showed that the puncture success rate was 95.5\% [24]. Koutouzis et al. [17] used a small sample randomized controlled study, and found that the puncture time of the d-TRA was longer than that of the c-TRA, but no significant difference in the total procedural time was noted between the two groups. The puncture time in the d-TRA group in this study was longer than that in the c-TRA group $[80(70,100)$ s vs. $60(60,66) \mathrm{s}, P<0.01]$. The procedure success rate in the d-TRA group was significantly lower than that in the c-TRA group $(90.94 \%$ vs. $96.49 \%, P=0.01)$. No significant differences in the puncture success rate, procedural method, procedural time, contrast dosage, or fluoroscopy time were noted between the two groups.

The reasons why the procedure success rate in the d-TRA was lower than that in the c-TRA may be explained the following aspects: (1) the diameter of the radial artery in the AS is smaller than that in the wrist [25], which makes it difficult to puncture or to insert the sheath after successful puncture; (2) tortuosity of the distal radial artery commonly exists, which easily leads to the failure of inserting the guidewire and sheath into the radial artery; and (3) for CAG and PCI, d-TRA is a new access that has recently emerged. Most operators lack puncture experience and need to overcome the learning curve.

Previous studies have found that the haemostasis time in d-TRA patients was significantly shorter than that in c-TRA patients [13, 16, 17]. Moreover, because compression in the distal radial artery does not block venous reflux of the hand, swelling, pain, and numbness of the hand do not easily occur. Thus, the patients are comfortable and the procedure is well tolerated [26]. Amin et al. [27] used the VAS to evaluate the degree of pain during haemostasis and found that the pain scores in the d-TRA group were significantly lower than those in the c-TRA group. AI-Azizi et al. [28] found that d-TRA not only 
improved patient satisfaction but also improved the satisfaction of operators and nurses. In this study, the time of haemostasis in the d-TRA group was significantly shorter than that in the c-TRA group $[4(3,6) \mathrm{h}$ vs. $6(6,8) \mathrm{h}$, $P<0.01]$, and the VAS was lower than that in the c-TRA group [3 $(2,3)$ vs. $4(3,5), P<0.01]$. These features, greatly reduce the nursing workload postprocedure and improve patient comfort and satisfaction.

d-TRA has very few complications, such as haematoma, haemorrhage, pseudoaneurysm and arteriovenous fistula [24, 28], which may be related to the AS with a bony basement surrounded by tendons. In this study, the rates of bleeding and haematoma in the d-TRA group were significantly lower than those in the c-TRA group. Further analysis found a significant difference in bleeding and haematoma in CAG patients, but not in PCI patients. This finding was due to the longer compression time in PCI patients compared with CAG patients in both the d-TRA group and the c-TRA group.

PSM can make the nonrandom data of two groups more similar and achieve covariate balance between the two groups, so the relationship between the research variables and the results can be better obtained [29]. In the present study, PSM was used to eliminate confounding bias and improve statistical effectiveness, which is one of the highlights of this study.

\section{Study limitations}

The study also has some limitations: (1) This study was a single-center prospective cohort study with a small sample size. Although PSM was adopted to eliminate confounding bias to the maximum extent, it could also make both groups so homogenous that differences may be underappreciated in the statistical analysis. These findings still needs to be verified by multicentre, large-sample, randomized controlled clinical trials. (2) Vascular ultrasound was not used to evaluate distal radial artery diameter, radial artery occlusion, pseudoaneurysm, or arteriovenous fistula in all patients. (3) Long long-term follow-up after the procedure is needed.

\section{Conclusions}

d-TRA is as safe and effective as c-TRA for CAG and PCI. It has the advantages of improved comfort and fewer complications.

\footnotetext{
Abbreviations

CAG: Coronary angiography; PCl: Percutaneous coronary intervention; $d$-TRA : Distal transradial artery access; C-TRA: Conventional transradial artery access; PSM: Propensity score matching; VAS: Visual analogue scale; CAD: Coronary atherosclerotic disease; AS: Anatomic snuffbox.
}

\section{Supplementary Information}

The online version contains supplementary material available at https://doi. org/10.1186/s12872-022-02518-8.

Additional file 1. Subgroup analysis of the puncture success rate in the d-TRA group stratified by sex, age, BMI, EH, DM, and smoking.

\section{Acknowledgements}

We thank all our colleagues at the Department of Cardiology, Wujin Hospital, affiliated with Jiangsu University, and nursing and technician staff in our catheterization laboratory.

\section{Authors' contributions}

GJC, FL and GWS, XLY wrote the main manuscript text and RXS, JQX, HMH, LML, LYZ and CG prepared figures and tables. All authors reviewed the manuscript. All authors read and approved the final manuscript.

\section{Funding}

This study was supported by Science and Technology Project of Wujin (No: WS202001) and the Jiangsu Youth Medical Talents Project (No: QNRC2016310). No funding body participated in the design of the study and collection, analysis, and interpretation of date and in writing the manuscript.

\section{Availability of data and materials}

The datasets used and/or analysed during the current study are available from the corresponding author on reasonable request.

\section{Declarations}

\section{Ethics approval and consent to participate}

The study conforms to the Declaration of Helsinki and was vetted and approved by the Ethics Committee of Wujin Hospital affiliated with Jiangsu University, and all the patients signed the informed consent form.

\section{Consent for publication}

Written informed consent was obtained from the patient for publication of this study and any accompanying images. A copy of the written consent is available for review by the editor of this journal.

\section{Competing interests}

The authors declare that they have no competing interests.

\section{Author details}

${ }^{1}$ Department of Cardiology, Wujin Hospital Affiliated with Jiangsu University, The Wujin Clinical College of Xuzhou Medical University, 2 North Yongning Road, Changzhou 213017, Jiangsu Province, People's Republic of China. ${ }^{2}$ Department of Ultrasonic, Wujin Hospital Affiliated with Jiangsu University, The Wujin Clinical College of Xuzhou Medical University, Changzhou 213017, Jiangsu Province, China.

Received: 14 August 2021 Accepted: 21 February 2022

Published online: 02 March 2022

\section{References}

1. GBD 2015 Mortality and Causes of Death Collaborators. Global, regional, and national life expectancy, all-cause mortality, and cause-specific mortality for 249 causes of death, 1980-2015: a systematic analysis for the Global Burden of Disease Study 2015. Lancet. 2016;388:1459-544.

2. Feldman DN, Swaminathan RV, Kaltenbach LA, Baklanov DV, Kim LK, Wong SC, et al. Adoption of radial access and comparison of outcomes to femoral access in percutaneous coronary intervention: an updated report from the national cardiovascular data registry (2007-2012). Circulation. 2013;127:2295-306 
3. Bajaj A, Pancholy S, Sothwal A, Nawaz Y, Boruah P. Transradial versus transfemoral access for percutaneous coronary intervention of unprotected left main coronary artery stenosis: a systematic review and meta-analysis. Cardiovasc Revasc Med. 2019;20:790-8.

4. Neumann FJ, Sousa-Uva M, Ahlsson A, Alfonso F, Banning AP, Benedetto $U$, et al. ESC scientific document group. 2018 ESC/EACTS guidelines on myocardial revascularization. Eur Heart J. 2019:40:87-165.

5. Aoun J, Hattar L, Dgayli K, Wong G, Bhat T. Update on complications and their management during transradial cardiac catheterization. Expert Rev Cardiovasc Ther. 2019;17:741-51.

6. Rashid M, Kwok CS, Pancholy S, Chugh S, Kedev SA, Bernat I, et al. Radial artery occlusion after transradial interventions: a systematic review and meta-analysis. J Am Heart Assoc. 2016;5:e002686.

7. Costa F, van Leeuwen MA, Daemen J, Diletti R, Kauer F, van Geuns RJ, et al. The Rotterdam radial access research: ultrasound-based radial artery evaluation for diagnostic and therapeutic coronary procedures. Circ Cardiovasc Interv. 2016;9:e003129.

8. Burzotta F, Trani C, Mazzari MA, Tommasino A, Niccoli G, Porto I, et al. Vascular complications and access crossover in 10,676 transradial percutaneous coronary procedures. Am Heart J. 2012;163:230-8.

9. Gragnano F, Branca M, Frigoli E, Leonardi S, Vranckx P, Di Maio D, et al. Access-site crossover in patients with acute coronary syndrome undergoing invasive management. JACC Cardiovasc Interv. 2021;14:361-73.

10. Gragnano F, Jolly SS, Mehta SR, Branca M, van Klaveren D, Frigoli E, et al. Prediction of radial crossover in acute coronary syndromes: derivation and validation of the MATRIX score. Eurolntervention. 2021;17:e971-80.

11. Kaledin AL, Kochanov IN, Seletskiĩ SS, Arkharov IV, Tla B, Kozlov KL. Peculiarities of arterial access in endovascular surgery in elderly patients. Adv Gerontol. 2014;27:115-9.

12. Roghani-Dehkordi F. Merits of more distal accesses in the hand for coronary angiography and intervention. In: Proceedings of the 4th international cardiovascular joint Congress in Isfahan; 2016. p. 24-25.

13. Kiemeneij F. Left distal transradial access in the anatomical snuffbox for coronary angiography (IdTRA) and interventions (IdTRI). Eurolntervention. 2017;13:851-7.

14. Cai G, Huang H, Li F, Shi G, Yu X, Yu L. Distal transradial access: a review of the feasibility and safety in cardiovascular angiography and intervention. BMC Cardiovasc Disord. 2020;20:356.

15. Vefalı V, Sarıçam E. The comparison of traditional radial access and novel distal radial access for cardiac catheterization. Cardiovasc Revasc Med. 2020;21:496-500

16. Aoi S, Htun WW, Freeo S, Lee S, Kyaw H, Alfaro V, et al. Distal transradial artery access in the anatomical snuffbox for coronary angiography as an alternative access site for faster hemostasis. Catheter Cardiovasc Interv. 2019;94:651-7.

17. Koutouzis M, Kontopodis E, Tassopoulos A, Tsiafoutis I, Katsanou K, Rigatou A, et al. Distal versus traditional radial approach for coronary angiography. Cardiovasc Revasc Med. 2019;20:678-80.

18. Wewers ME, Lowe NK. A critical review of visual analogue scales in the measurement of clinical phenomena. Res Nurs Health. 1990;13:227-36.

19. Mehran R, Rao SV, Bhatt DL, Gibson CM, Caixeta A, Eikelboom J, et al. Standardized bleeding definitions for cardiovascular clinical trials: a consensus report from the Bleeding Academic Research Consortium. Circulation. 2011;123:2736-47.

20. Bertrand OF, De Larochellière R, Rodés-Cabau J, Proulx G, Gleeton O, Nguyen CM, et al. A randomized study comparing same-day home discharge and abciximab bolus only to overnight hospitalization and abciximab bolus and infusion after transradial coronary stent implantation. Circulation. 2006;114:2636-43.

21. Amato JJ, Solod E, Cleveland RJ. A "second" radial artery for monitoring the perioperative pediatric cardiac patient. J Pediatr Surg. 1977;12:715-7.

22. Aminian A, Sgueglia GA, Wiemer M, Gasparini GL, Kefer J, Ruzsa Z, et al. Distal versus conventional radial access for coronary angiography and intervention: Design and rationale of DISCO RADIAL study. Am Heart J. 2021;244:19-30.

23. Valsecchi O, Vassileva A, Cereda AF, Canova P, Satogami K, Fiocca L, et al. Early clinical experience with right and left distal transradial access in the anatomical snuffbox in 52 consecutive patients. J Invasive Cardiol. 2018:30:218-23

24. Lee JW, Park SW, Son JW, Ahn SG, Lee SH. Real-world experience of the left distal transradial approach for coronary angiography and percutaneous coronary intervention: a prospective observational study (LeDRA). Eurolntervention. 2018;14:e995-1003.

25. Hull JE, Kinsey EN, Bishop WL. Mapping of the snuffbox and cubital vessels for percutaneous arterial venous fistula (pAVF) in dialysis patients. J Vasc Access. 2013;14:245-51.

26. Sgueglia GA, Di Giorgio A, Gaspardone A, Babunashvili A. Anatomic basis and physiological rationale of distal radial artery access for percutaneous coronary and endovascular procedures. JACC Cardiovasc Interv. 2018;11:2113-9.

27. Amin MR, Singha CK, Banerjee SK, Hoque H, Mahabub EE, Hoque M, et al. Comparison of distal transradial in the anatomical snuffbox versus conventional transradial access for coronary angiography and interventionan experience in 100 cases. Univ Heart J. 2017;13:40-5.

28. Al-Azizi KM, Grewal V, Gobeil K, Maqsood K, Haider A, Mohani A, et al. The left distal transradial artery access for coronary angiography and intervention: a US experience. Cardiovasc Revasc Med. 2019;20:786-9.

29. Haukoos JS, Lewis RJ. The propensity score. JAMA. 2015;314:1637-8.

\section{Publisher's Note}

Springer Nature remains neutral with regard to jurisdictional claims in published maps and institutional affiliations.
Ready to submit your research? Choose BMC and benefit from:

- fast, convenient online submission

- thorough peer review by experienced researchers in your field

- rapid publication on acceptance

- support for research data, including large and complex data types

- gold Open Access which fosters wider collaboration and increased citations

- maximum visibility for your research: over $100 \mathrm{M}$ website views per year

At BMC, research is always in progress.

Learn more biomedcentral.com/submissions 